\title{
Analysis of evoked lumbosacral potentials in man
}

\author{
J . D E L B E K E, A. J . M c COM A S ${ }^{1}$, A N D S J . K O P E C \\ From the Medical Research Council Developmental Neurobiology Research Group and Department \\ of Medicine (Neurology), McMaster University, Hamilton, Ontario, Canada
}

\begin{abstract}
SUM M ARY Surface electrodes have been used to record potentials evoked in the lumbosacral region of 15 healthy volunteers after tibial nerve stimulation. By monitoring the $M$ waves and $H$ reflexes in the triceps surae muscles and by comparing the responses recorded over the roots with those over the lower cord, it was possible to identify the neural substrates responsible for several of the components in the responses. The findings are compared with those of previous studies in man and in other mammalian preparations.
\end{abstract}

The first successful attempt at recording evoked potentials in the human spinal cord appears to have been that of Magladery et al. (1951) who were able to identify several components in the response. The recording technique used by these authors involved the insertion of stiff wire electrodes into the subarachnoid space at different vertebral levels. Although a similar approach has since been used by other workers (Ertekin, 1973; Caccia et al., 1976), the advantages of the method must be carefully balanced against the disadvantages. Apart from the pain and inconvenience of using needle electrodes in this way, such side effects as headache-presumably due to leakage of cerebrospinal fluid-and transient pyrexia have been described (Ertekin, 1976). A more serious problem is the difficulty in manipulating the electrode so that, after penetrating the extremely tough dura mater and the less dense arachnoid mater, its tip can be brought to lie within the relatively small confines of the subarachnoid space overlying the cord. While accepting the absence of any permanent neurological deficits reported to date, there is obviously a risk that the electrode may advance too far and either penetrate or bruise the cord. Indeed, the description of sensory symptoms referred to a level caudal to the penetration and the surprisingly large amplitudes of some of the evoked potentials that have been recorded (up to $440 \mu \mathrm{V}$; Ertekin, 1976) are

\footnotetext{
${ }^{1}$ Address for correspondence and reprint requests: Dr Alan McComas, Room 4U7, McMaster University Medical Centre, 1200 Main St. West, Hamilton, Ontario, Canada L8S 4J9.

Accepted 13 October 1977
}

difficult to reconcile with a purely subarachnoid recording.

An alternative and less hazardous approach, which still enables responses of reasonable amplitude to be obtained, is that described by Shimoji et al. (1971); in this technique fine flexible wires are introduced into the epidural space through an anaesthetic needle of the Tuohy type.

The third approach, and the one which has been employed in the present study, is to use surface recording electrodes. This method was first used by Liberson and Kim (1963) but more recently has been developed and successfully exploited in Cracco's laboratory (Cracco, 1973; Cracco et al., 1975). In the present study it will be shown that in suitable normal subjects the method is capable of yielding technically satisfactory responses. By taking advantage of the anatomical features of the lumbosacral region, in which substantial lengths of dorsal and ventral root fibres are available for study below the termination of the cord, it has been possible to determine the origins of the major components of the evoked response.

\section{Subjects and methods}

Experiments were conducted on 15 healthy volunteers of both sexes, aged 2 to 49 years; some were examined on several occasions. Informed consent was obtained before investigation from each of the subjects (or their parents) and the experimental procedure had the approval of the Ethics Committee of the Research Advisory Group at McMaster University. During the recording the subjects lay supine on a couch in a room maintained at $22^{\circ} \mathrm{C}-25^{\circ} \mathrm{C}$; the legs were not warmed 
and they rested on pillows so that the knees were flexed by about $60^{\circ}$.

\section{STIMULATION}

In most experiments the tibial nerves of both legs were stimulated simultaneously. The electric shocks were delivered through pairs of relatively large electrodes $(30 \mathrm{~mm} \times 40 \mathrm{~mm})$ made of lead; on each leg one electrode was placed on the skin overlying the popliteal fossa and acted as a cathode; the anode was attached just below the patella. Rectangular voltage pulses, 0.5 or $1 \mathrm{~ms}$ in duration, were delivered from a Devices Ltd stimulator type 3072 . The stimuli were given at a rate of $0.5 \mathrm{~Hz}$ or less determined by a digital timing device (Devices Ltd digitimer type 32090). Because of difficulties encountered through the recording of the electrocardiogram (ECG), the digitimer was triggered from the ECG and the command pulse to the stimulator was delayed until the ECG had entered an isoelectric phase.

\section{RECORDINGS}

The recording electrodes consisted of chlorided silver strips, $50 \mathrm{~mm}$ long and $6 \mathrm{~mm}$ wide, coated with conducting cream. After the skin had been prepared by rubbing with alcohol and then with conducting cream, the impedance of a pair of electrodes on the skin was less than $10 \mathrm{k} \Omega$. The electrodes were arranged on the back so as to lie transversely across the midline at levels of identified spinous processes. The reference electrode was placed at $\mathrm{T} 6$ spinous process since at this level the response evoked by stimulation of the tibial nerve was quite small while involuntary activity in the paraspinal muscles was least troublesome. Recordings could be made from up to four stigmatic electrodes simultaneously. $H$ reflexes and $M$ waves were monitored by two silver strips $30 \mathrm{~mm} \times$ $6 \mathrm{~mm}$, fastened to the skin over the soleus muscle. Two large lead plates acted as ground electrodes and were attached to the lateral aspect of each thigh. In some experiments evoked potentials were recorded from the leg area of the contralateral somatosensory cortex using conventional techniques described elsewhere (Giblin, 1964).

The differential amplifiers used for recording had input impedances of $10 \mathrm{M} \Omega$ and were used with frequency responses of $2 \mathrm{~Hz}-3 \mathrm{kHz}$. Averaging was performed by a Hewlett-Packard signal analyser (HP type 5480) with two channels or by an ANOPS computer with four channels. The averaged responses (of 64 or fewer trials) were either photographed or else drawn out by means of a programmable calculator (HP type 9810A) connected to an X-Y plotter (HP type 9862A).

\section{Results}

FORM AND SPATIAL DISTRIBUTION OF THE EVOKED RESPONSES

Figure 1 (left) shows the distribution of the evoked potentials throughout the length of the spinal cord in a 49 year old man, after stimulation of both tibial nerves at intensities maximal for the $\mathrm{H}$ reflexes. For this experiment only, two reference electrodes were used and were attached to the lobes of the ears. An evoked response could be easily distinguished at the levels of the T11, L2, and $\mathrm{S} 1$ spinous processes but at $\mathrm{T} 6$ it had declined to approximately $20 \%$ of its maximal amplitude. At more rostral levels the response could no longer be seen; the nature of the small late positivity in the recordings at $\mathrm{C} 2$ and $\mathrm{C} 5$ spinous processes was not investigated but a cerebral origin was suspected. The possibility of simultaneously recording from the somatosensory cortex and from the lumbosacral region was exploited in only a few of the experiments and an example is shown in Fig. 1 (right); in this case the conduction time between T12 spinous process and cortex was approximately $12.5 \mathrm{~ms}$.

A more thorough analysis of the distribution of the evoked responses within the lumbosacral region is given in Fig. 2 (upper). It can be seen that the potentials were largest at $\mathrm{T} 12$ spinous process, where they consisted of a complex negative wave followed by a prolonged positivity. An attenuated negative potential, but without a succeeding positivity, was present at $\mathrm{T} 9$ spinous process. In a caudal direction, large potentials were present at L2 but at L4 and S1 spinous processes the potentials were noticeably different in that the initial negative response began earlier and was clearly separated from a later negative wave.

In another experiment on the same subject used for the recordings in Fig. 2 (upper), it was possible to study the configuration of the potentials evoked at $\mathrm{T} 12$ and $\mathrm{S} 1$ spinous processes in more detail (Fig. 2, lower). At T12 it could be seen that a small positivity preceded the first negative deflection. The negativity itself was revealed as a complex wave containing three components. Although these records were taken from a 2 year old boy, similar but less well-demarcated components were found in recordings from adults, as in Figs. 1 and 3. That these components were not due to asynchronous activation of neural elements on the two sides of the cord, after stimulation of both legs, was shown by the responses to stimulation of each leg separately. Not only were similar individual components present after stimulation of either leg, but corresponding waves underwent 

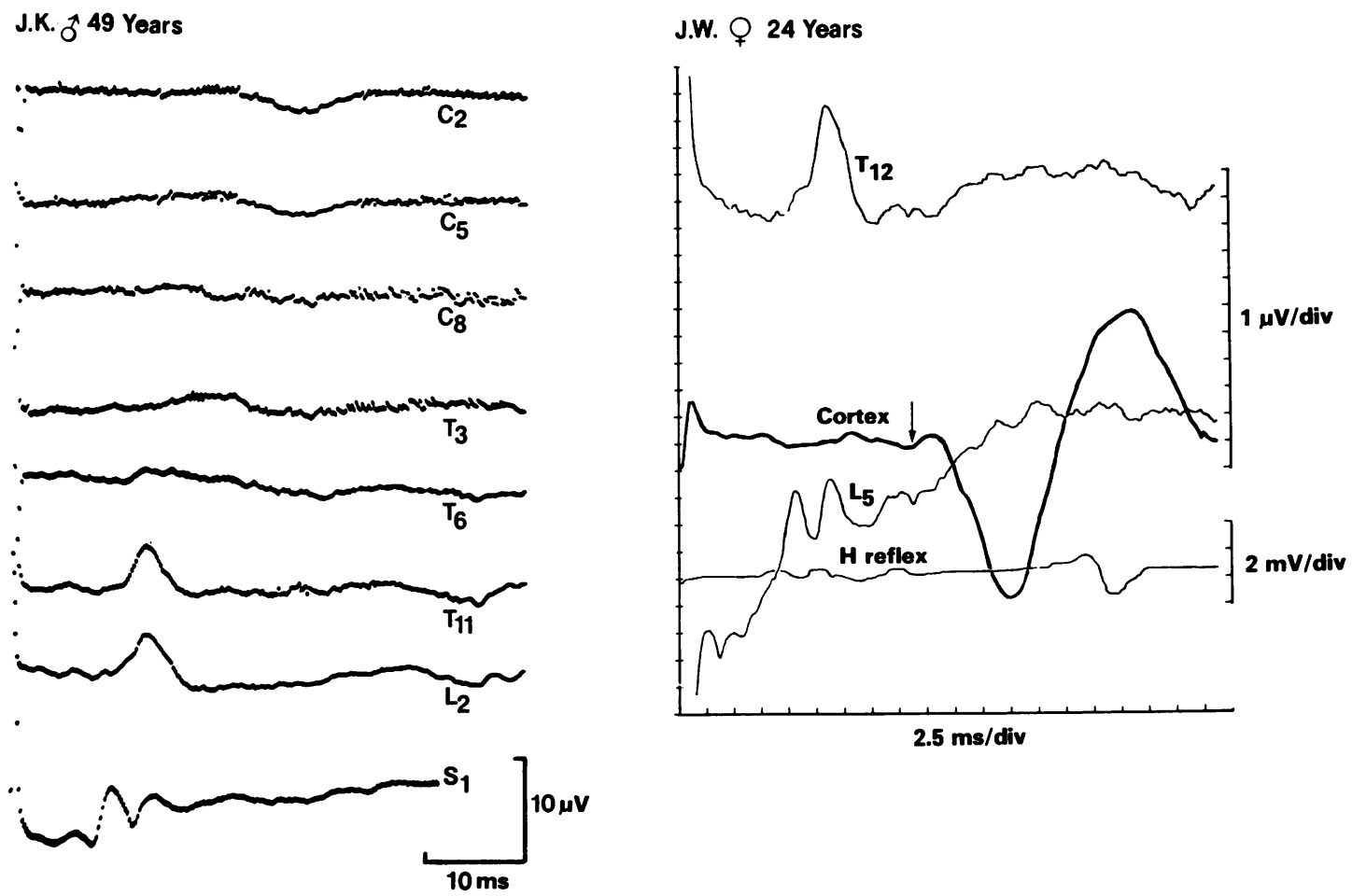

Fig. 1 Left: potentials evoked at different levels of spinal cord in a 49 year old man after stimulation of both tibial nerves at intensities for maximal $\mathrm{H}$ reflexes; reference electrodes on earlobes. In this and other figures negativity of stigmatic electrode is shown as upward deflection. Right: potentials evoked at L5 and $T 12$ levels and over contralateral somatosensory cortex in a 24 year old woman after stimulation of both tibial nerves at intensities for maximal $H$ reflexes. Onset of cortical response shown by arrow.

summation when the two limbs were stimulated simultaneously. It should be noted that the peak of the negative wave, corresponding to the third negative component, had a similar latency between T6 and L2 levels (Fig. 1, left and Fig. 2, upper).

Summation of the evoked potentials was equally evident when an examination was made of the responses at $\mathrm{S} 1$ after stimulation of either or both legs (Fig. 2, lower). At this level also it was apparent that the first negative wave was preceded by a small positivity. As in Fig. 1 (right) the evoked activity began earlier at the more caudal level, the latencies of the initial negativity in Fig. 2 being $4.3 \mathrm{~ms}$ and $5.5 \mathrm{~ms}$ respectively at the $\mathrm{S} 1$ and $\mathrm{T} 12$ levels. After the second negative wave at S1 there was a positive wave, well seen in Fig. 3, which had a shorter duration than the late positivity at $\mathrm{T} 12$ spinous process. Finally, there was a rather small rounded negative wave which is also evident in Figs. 1 (right), 2 (lower), and 3 (upper and lower).

\section{LATENCY MEASUREMENTS}

The Table shows the latencies of evoked responses, measured to the onsets of the initial negative deflections at S1 (or L5) and T12 levels. It was not possible to make these measurements with a resolution greater than $0.25 \mathrm{~ms}$. Since the mean difference in latency between the two levels was about $2 \mathrm{~ms}$, the error due to the combined measurement could have amounted to $25 \%$. For the 14 adults and older children the mean response latencies at L5/S1 and at T12 levels were 8.8 and $10.6 \mathrm{~ms}$ respectively. These values corresponded to mean conduction velocities of $67.1 \mathrm{~m} / \mathrm{s}$ from the $\mathrm{knee}$ to $\mathrm{L} 5 / \mathrm{S} 1$ and of $80.6 \mathrm{~m} / \mathrm{s}$ between L5/S1 and $\mathrm{T} 12$ spinous processes. In the youngest subject, a 2 year old boy, impulses were conducted between $\mathrm{S} 1$ and T12 levels with a maximum velocity of $40 \mathrm{~m} / \mathrm{s}$, a value well below the lower limit found for adults $(54 \mathrm{~m} / \mathrm{s})$. Estimates of conduction velocity based on measurements of latency to the peaks of the first main negative deflections were 


\section{P.D. O'2 Years}
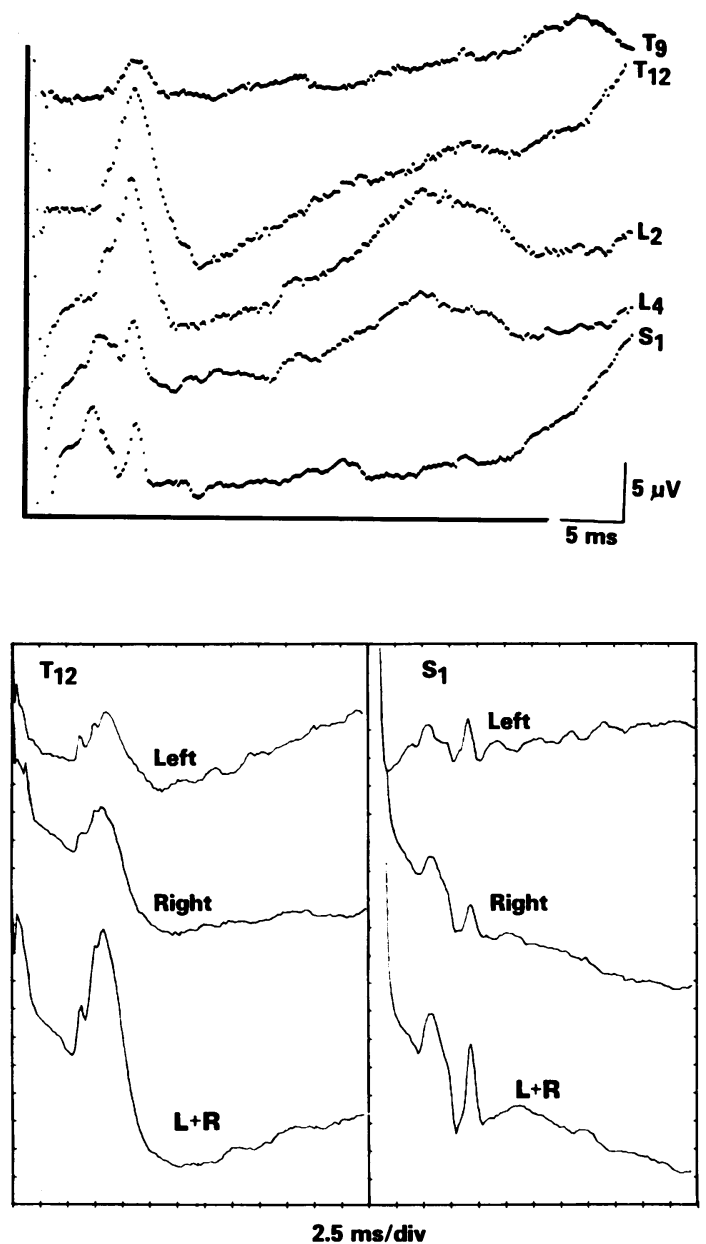

Fig. 2 Evoked potentials in 2 year old boy. Upper: spatial distribution of potentials in T9-S1 region after stimulation of both tibial nerves. Lower: additive effects of stimulating both tibial nerves simultaneously at $T 12$ and S1. Vertical calibration: $2 \mu \mathrm{V} /$ division. For all experiments the stimulus intensities were set for maximal $H$ reflexes.

not performed since it is probable that these waves have different origins at the T12 and S1 levels (see below). Gross estimates of conduction velocity were also made between T12 spinous process and the contralateral somatosensory cortex (Fig. 1, right) in several subjects and were approximately $60 \mathrm{~m} / \mathrm{s}$.

EFFECTS OF STIMULUS INTENSITY

In the majority of subjects studies were made of the effects of stimulus intensity on the evoked responses. The stimulus intensities chosen were those yielding $\mathrm{H}$ reflexes with amplitudes which were respectively half-maximal, maximal, and equal to the $M$ wave amplitude; in most subjects an intensity corresponding to the maximum $\mathbf{M}$ wave was also used. The results obtained in the two subjects yielding the largest responses, a 2 year old boy and a 29 year old woman, are shown in Fig. 3.

At T12 it can be seen that in both subjects there were substantial negative and positive waves at stimulus intensities which were subthreshold or just threshold for motor fibres. These observations indicate that the potentials were evoked by activity in sensory fibres rather than by the consequences of antidromic impulses in motor nerve fibres. As the stimulus intensity was raised so as to excite a larger proportion of the motor fibres, the $\mathrm{H}$ reflex declined due to collision between the reflexly elicited and antidromically conducted impulses in the motor axons (Magladery and McDougal, 1950). Such stimuli would be expected to excite increasing numbers of afferent fibres in addition to motor fibres, and this is presumably why the evoked responses showed further growth (Fig. 3, upper).

At $S 1$ the initial positivity and negativity were closely related to the stimulus intensity. As at the T12 level, substantial responses were present with stimulus intensities below threshold for motor fibres, indicating that they had been induced by activity in sensory fibres. The second main negative component paralleled the $H$ reflex, being largest when the latter was maximal and declining as the stimulus intensity was raised further (Figs. 3 and 4). This behaviour strongly suggested that the later negative wave was largely due to a reflex volley of impulses in motor fibres. In adults, however, this wave never completely disappeared even when the $\mathrm{H}$ reflex had been eliminated by stronger stimuli (Fig. 4). This discrepancy suggests that there may have been a small component with an origin other than the $\mathrm{H}$ reflex volley. Also visible in the upper record of Fig. 3 (arrow) is a small negative wave at the termination of the initial large deflection (see Discussion).

\section{RESPONSES TO PAIRED STIMULATION}

In subjects yielding good responses the effects of paired stimulation were studied. For conditioning test intervals of $3 \mathrm{~ms}$ or less a subtraction technique (see Kopec et al., 1978) was used to reveal the test response alone from the overlapping responses from the two stimuli. In Fig. 5 (upper) it can be seen that only a small early negative potential was present at L5 and T12 level when a conditioning test interval of $2 \mathrm{~ms}$ was used; this 
Table Impulse conduction times and velocities, measured from knee to L5 or S1 and from L5/S1 to T12. $V$ alues in youngest subject $(P D)$ not used in estimations of means

\begin{tabular}{|c|c|c|c|c|c|c|c|}
\hline \multirow[b]{2}{*}{ Subject } & \multirow[b]{2}{*}{$\begin{array}{l}\text { Age } \\
(y r)\end{array}$} & \multicolumn{3}{|c|}{ Knee $\rightarrow L 5 / S I$} & \multicolumn{3}{|c|}{$L 5 / S 1 \rightarrow T 12$} \\
\hline & & $\begin{array}{l}\text { Distance } \\
\text { (cm) }\end{array}$ & $\begin{array}{l}\text { Conduction } \\
\text { time } \\
(\mathrm{ms})\end{array}$ & $\begin{array}{l}\text { Conduction } \\
\text { Velocity } \\
(\mathrm{m} / \mathrm{s})\end{array}$ & $\begin{array}{l}\text { Distance } \\
(\mathrm{cm})\end{array}$ & $\begin{array}{l}\text { Conduction } \\
\text { time } \\
\text { (ms) }\end{array}$ & $\begin{array}{l}\text { Conduction } \\
\text { Velocity } \\
(\mathrm{m} / \mathrm{s})\end{array}$ \\
\hline (PD) & 2 & 26 & 4.25 & 61 & 6 & 1.50 & 40) \\
\hline AMcC & 10 & 46.5 & 6.75 & 69 & 13 & 1.50 & 87 \\
\hline TZ & 13 & 46.5 & 6.75 & 54 & 11 & 2.0 & 55 \\
\hline $\mathbf{C Z}$ & 16 & 59 & 8.75 & 67 & 11 & 1.50 & 73 \\
\hline $\mathbf{E W}$ & 22 & 62 & 8.75 & 71 & 18 & 1.75 & 103 \\
\hline EJ & 22 & 64 & 9.50 & 67 & 14.5 & 2.25 & 64 \\
\hline DD & 23 & 62 & 9.50 & 65 & 17 & 1.75 & 97 \\
\hline WK & 23 & 67 & 10.00 & 67 & 19 & 1.75 & 108 \\
\hline JW & 24 & 61 & 9.00 & 68 & 13 & 1.75 & 74 \\
\hline HE & 26 & 58 & 8.25 & 70 & 19 & 3.25 & 59 \\
\hline FD & 29 & 60 & 9.25 & 65 & 15 & 1.50 & 100 \\
\hline JD & 29 & 60 & 8.50 & 71 & 18 & 2.0 & 90 \\
\hline DP & 42 & 51 & 8.50 & 60 & 16 & 1.75 & 91 \\
\hline OP & 45 & 60 & 8.50 & 71 & 15 & 2.00 & 75 \\
\hline JK & 49 & 63 & 10.50 & 60 & 16.5 & 2.0 & 83 \\
\hline Mean & & 58.6 & 8.75 & 67.1 & 15.4 & 1.91 & 80.6 \\
\hline \pm SD & & 6.2 & 1.06 & 3.6 & 2.7 & 0.45 & 16.7 \\
\hline
\end{tabular}

potential was thought to be the afferent volley in the dorsal roots and dorsal column respectively. At an interval of $3 \mathrm{~ms}$ there was full recovery of the sensory fibres at L5 level and a later negative wave, representing postsynaptic activity (see Discusion) was now present at T12. At this interval the second negative deflection, reflecting the reflex discharge in ventral root fibres, was present. At 10-30 ms intervals the main negative deflection at $\mathrm{T} 12$ spinous process was still diminished in relation to the control response to a conditioning stimulus (bottom trace in Fig. 5, lower). Interestingly, the slow positive wave did not demonstrate such prolonged refractoriness for the responses to conditioning and test shocks were found to summate at intervals of 3-10 ms (Fig. 5, lower). The second negative wave at $S 1$ level, although present at conditioning test intervals of 3-5 ms, was absent at intervals of $10-15 \mathrm{~ms}$, and was again present at 20-30 ms.

\section{Discussion}

The lumbosacral region was chosen for this study because it afforded the possibility of differentiating impulse activity in the long roots of the cauda equina from postsynaptic responses at more rostral levels. A similar approach was used in the pioneering study of Magladery et al. (1951) but until now does not appear to have been repeated in a systematic manner. The findings of the two studies appear remarkably similar and can be discussed with the help of Fig. 6 which shows, in diagrammatic form, the responses recorded at T12 and S1 levels after tibial nerve stimulation at intensities maximal for the $\mathrm{H}$ reflex and $\mathrm{M}$ wave respectively.

There can be little doubt that the first negative deflection with its small antecedent positivity (DR, DC in Fig. 6) is caused by action potentials conducted in sensory fibres which are running in the dorsal roots (at $\mathrm{S} 1$ ) and then in the dorsal columns (at T12 level). Thus the potential is present when only sensory fibres are activated, it is largest over the cauda equina, and a corresponding intramedullary spike potential has been identified in recordings from the dorsal surface of the cord in other mammals (Gasser and Graham, 1933). The difference in latency between the two spinal levels would be compatible with the conduction of impulses with a velocity of about $80 \mathrm{~m} / \mathrm{s}$. While the full triphasic form of the afferent volley is evident at $\mathrm{S} 1$, the concluding positive wave is obscured by succeeding negative waves at T12 spinous process. It is not clear, however, why the absolutely refractory period should be as long as $3 \mathrm{~ms}$ for most dorsal root fibres (or even longer, taking into account impulse slowing during the relatively refractory period) since peripheral nerve axons of comparable conduction velocities have values in the 0.4-1.0 ms range (Gilliatt and Willison, 1963; Lowitzsch and Hopf, 1972). A possible site for increased refractoriness in sensory axons would be their junctions with the dorsal root ganglion cells.

The second main negative deflection at $\mathrm{S} 1$ level can also be identified with confidence. The fact that its latency is longer than that of the dorsal root volley, the proportional correspondence between its amplitude and that of the $\mathrm{H}$ reflex as the stimulus intensity is varied, and its presence over the cauda equina, all indicate that this potential is 
P.D.ơ2 Years $T_{12}$

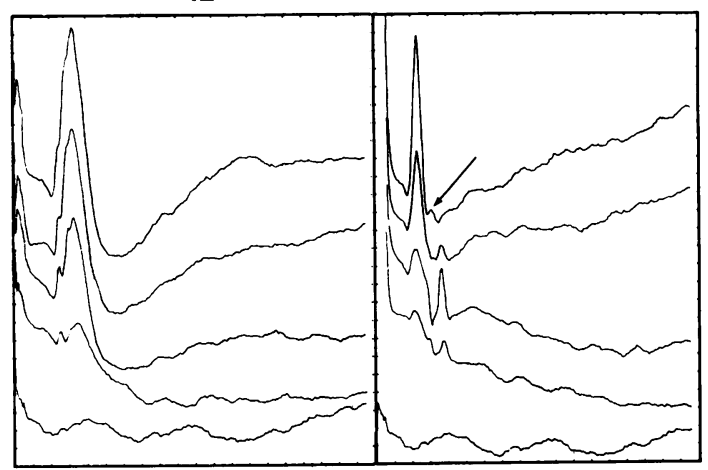

]

F.D. 29 Years

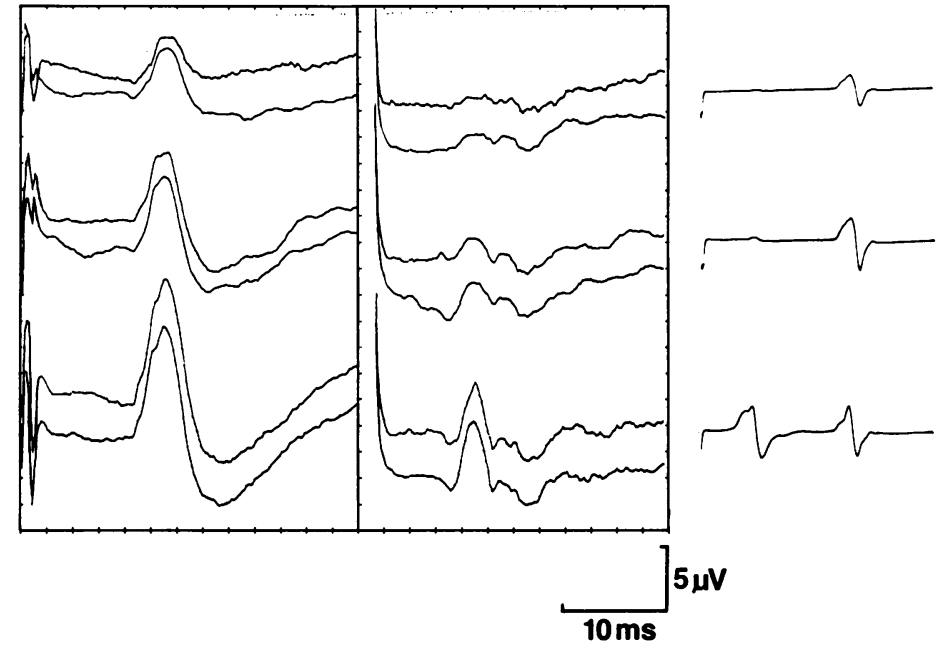

$H$ reflex

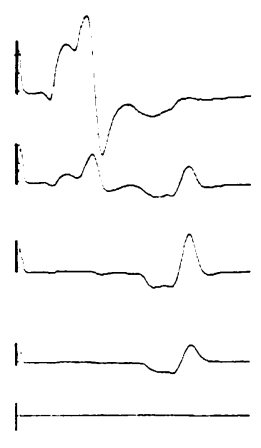

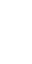<smiles>C1CCCCC1</smiles>

a reflexly elicited volley in the ventral root fibres (VRr in Fig. 6). It is interesting that, unlike the findings of Magladery et al. (1951), the VR r potential was never recorded without a DR wave being present. The explanation for this discrepancy can only lie in the different methods of recording in the two studies; although the responses in the dorsal and ventral roots were much smaller in the present investigation, their relative sizes would not have been so susceptible to variation through inconsistencies in electrode placement as when intrathecal recordings were made. In adults, as opposed to young children, it is possible that a small part of the second negative wave at S1 spinous process is due to electrotonic conduction of the $\mathrm{N}_{1 \mathrm{~b}}$ potential (see below) from the termination of the spinal cord. This possibility is suggested by the observations that the wave does not completely disappear when the $\mathrm{H}$ reflex is suppressed by strong stimuli and that the latency to the peak of the second negative wave at $\mathrm{S} 1$ corresponds to that of the $\mathrm{N}_{1 \mathrm{~b}}$ potential at T12 level. 


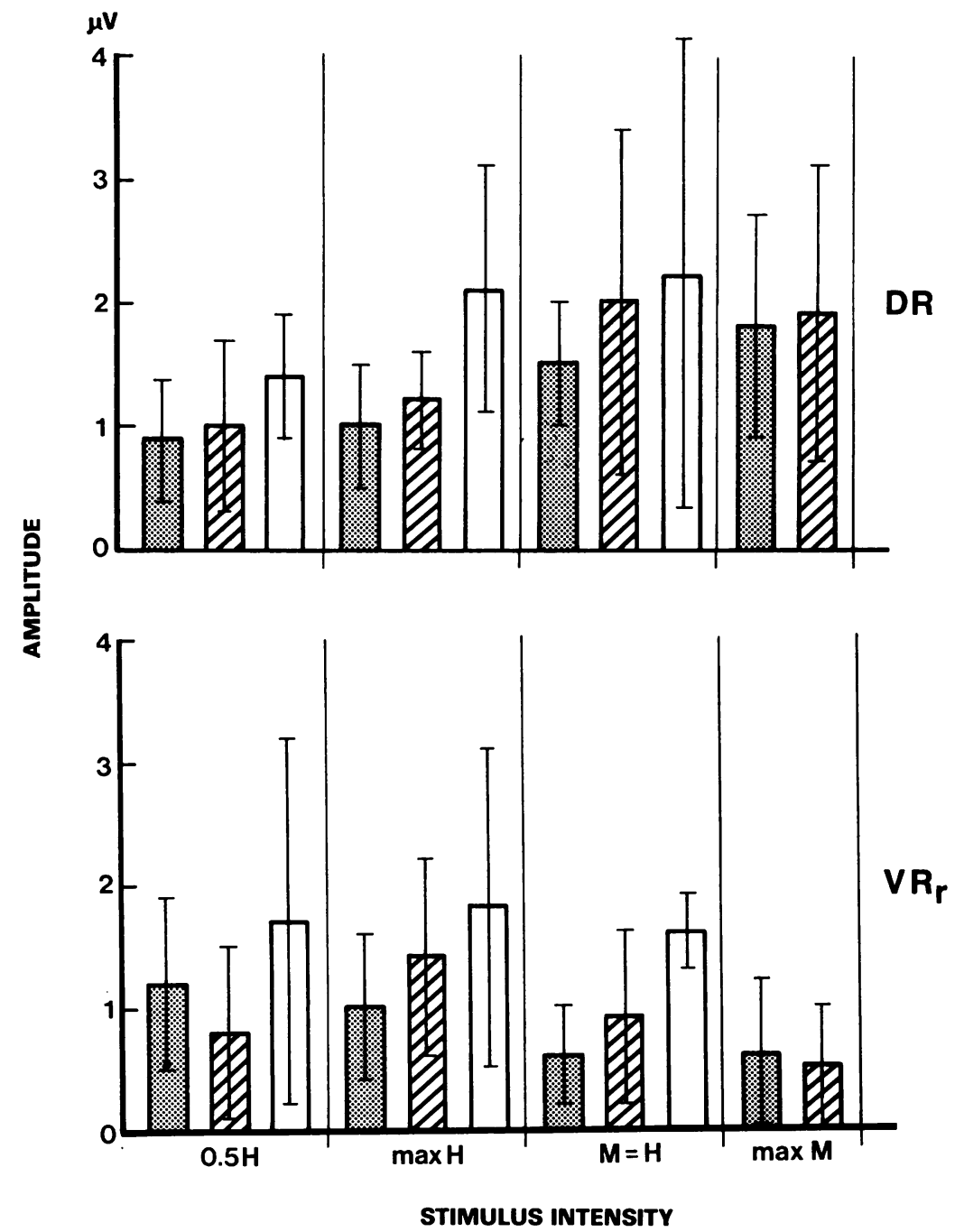

Fig. 4 Mean ( $\pm 1 S D)$ amplitudes of dorsal root $(D R)$ and ventral root reflex $\left(V R_{r}\right)$ potentials at $L 5 / S 1$ in control population for different stimulus intensities. Stippled, hatched, and open columns denote pooled values for stimulation of left, right, and both tibial nerves respectively.

In contrast to the two potentials already considered there is doubt concerning the origin of the small negative wave at $\mathrm{S} 1$ which can be seen at the conclusion of the first main negative wave when large stimulus intensities are used. Magladery et al. (1951), who also described this potential, believed it to be the antidromic volley in $\alpha$ motor fibres in the ventral roots. However, the potential is very much smaller than the $H$ reflex volley in the ventral roots $\left(V_{R}\right)$ whereas it should be larger, since more fibres would be excited. Also, the latency of this potential is almost double that of the DR deflection whereas the maximum conduction velocity of $\alpha$-motor fibres in the leg is only about $10 \%$ less than that of the $1 \mathrm{~A}$ fibres (Magladery et al., 1951); a greater difference in velocity was, however, found by Eisen et al. (1977), using an indirect technique. Although the fibres responsible for the small late wave might be slowly conducting afferent fibres, rather better candidates would be the $\gamma$-motor fibres since these form a substantial and relatively homogeneous 


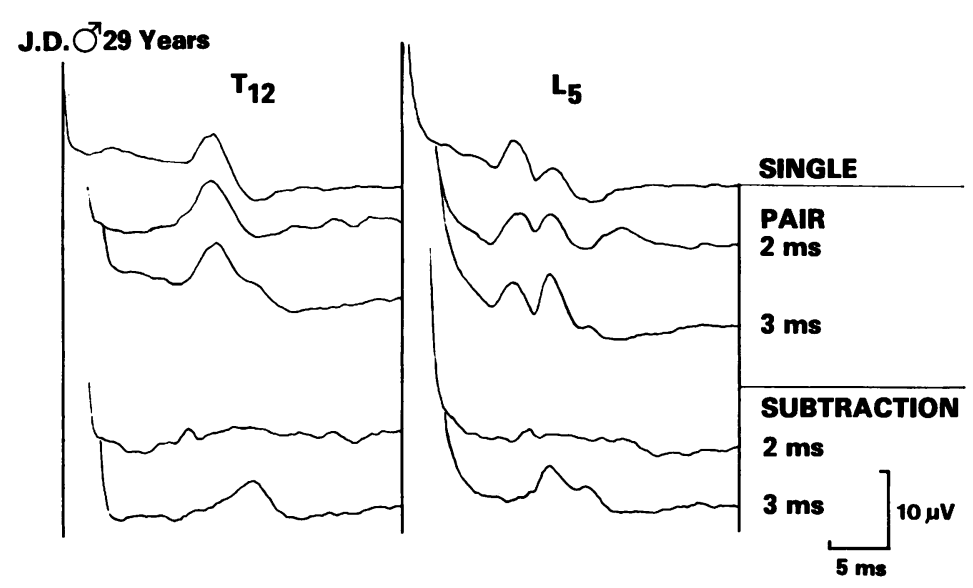

P.D. O'2 Years

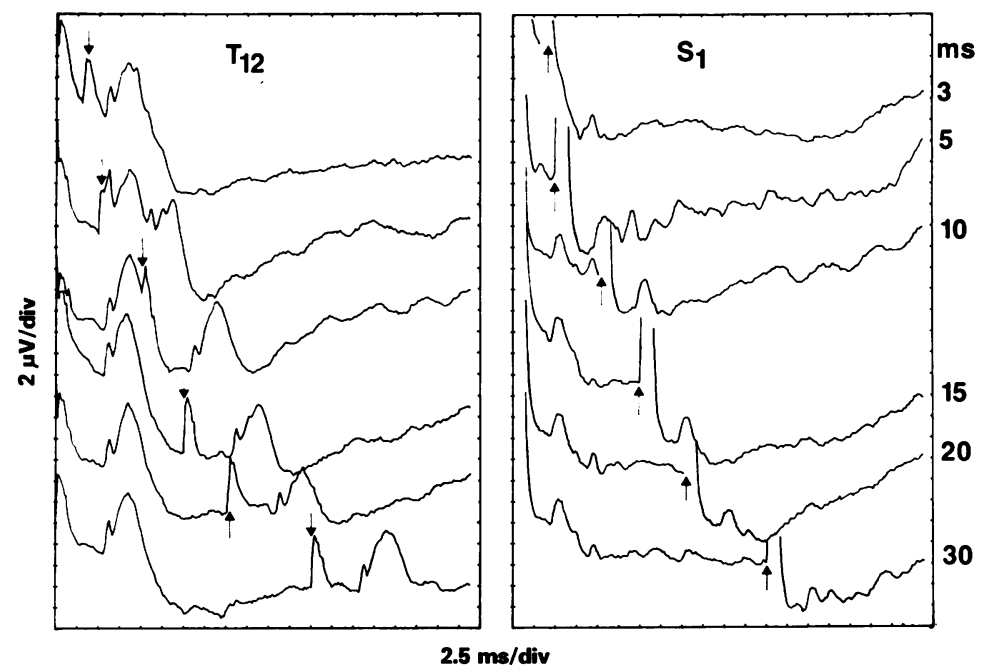

Fig. 5 Results of paired stimulation of both tibial nerves, using stimulus intensities for maximal $\mathrm{H}$ reflexes. Intervals between conditioning and test shocks given at right. In upper section a computer subtraction technique was used to extract the responses to testing shocks (see text). In lower section the times of the testing shocks are indicated by arrows.

population within the ventral roots. If the last interpretation is correct it follows that, at stimulus intensities adequate to excite motor fibres, the initial negative deflection at $\mathrm{S} 1$ will comprise antidromic impulses in $\alpha$-motor fibres as well as the DR component.

Reports of studies on mammals are helpful in enabling identification to be made of the potentials which follow the DC deflection at T12 level. The next notch on the upstroke of the main negative wave has been termed $\mathrm{N}_{1 \mathrm{a}}$ by Austin and McCouch (1955), the whole negative complex itself being $N_{1}$. Several types of evidence suggested to these authors that $\mathrm{N}_{1 \mathrm{a}}$ was most likely to be due to activity in the terminations of sensory fibres within the dorsal horn. The remainder of $\mathrm{N}_{1}$, referred to as $\mathrm{N}_{1 \mathrm{~b}}$ by Austin and McCouch, is accepted as being due to depolarisation of internuncial neurones and relay cells within the dorsal horn. The long positive wave ( $P$ in Fig. 6 ), which follows $N_{1}$ and was originally described by Gasser and Graham (1933), is now known to be due to synaptically mediated depolarisation of the terminals of the incoming sensory fibres (Wall, 1958). This activity, 

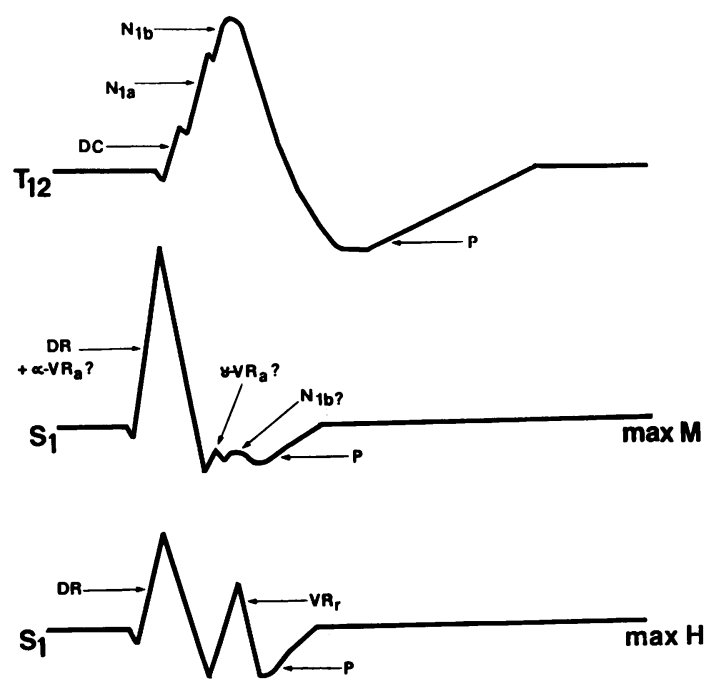

Fig. 6 Provisional analysis of components in evoked responses at S1 level (using two stimulus intensities) and at T12. Identity of waves: DC, dorsal column; DR, dorsal root; $N$, negative; $P$, positive; $V R$, ventral root; $a$, antidromic; $r$, reflex; see text.

the primary afferent depolarisation (PAD) of Eccles et al. (1962), is responsible for presynaptic inhibition. It is known that this activity can be conducted electrotonically along the dorsal roots, and this may explain the late positivity recorded at S1 level. Both the $\mathrm{N}_{1}$ and $\mathrm{P}$-waves are largely due to activity in cutaneous afferent fibres, the muscle afferent fibres making a smaller contribution (Bernhard, 1953). It is relevant that in other experiments we have been able to record small $\mathrm{N}_{1}$ and $P$-waves after stimulation of the sural nerve, which is thought to contain only cutaneous fibres. It should be noted that the $\mathrm{N}_{1}$ and $\mathrm{P}$-waves correspond to the $S$ (spinal) potentials of Magladery et al. (1951). The $P$-wave is described as $P_{2}$ by Shimoji et al. (1972), to distinguish it from the initial positivity of the evoked responses. Since the latter can now be assigned to the dorsal root and dorsal column volleys (see above), it is perhaps unnecessary to give it a separate identification.

In presenting these results there is no associated implication that the methods employed are necessarily the most appropriate for recording spinal evoked responses. It is clear, nonetheless, that in suitable subjects a meaningful analysis can be made of the electrophysiology of the human spinal cord using a harmless recording technique. At the same time these and similar techniques open new perspectives for exploring the derangements of spinal cord function in disease.
We wish to acknowledge the technical help of Glenn Shine and the secretarial assistance of Norma Zimmerman.

\section{References}

Austin, G. M., and McCouch, G. P. (1955). Presynaptic component of intermediary cord potential. Journal of Neurophysiology, 18, 441-451.

Bernhard, C. G. (1953). The spinal cord potentials in leads from the cord dorsum in relation to the peripheral source of afferent stimulation. Acta Physiologica Scandinavica, 29, Suppl. 106, 1-29.

Caccia, M. R., Ubiali, E., and Andreussi, L. (1976). Spinal evoked responses recorded from the epidural space in normal and diseased humans. Journal of Neurology, Neurosurgery, and Psychiatry, 39, 962972.

Cracco, J. B., Cracco, R. Q., and Graziani, L. J. (1975). The spinal evoked responses in infants and children. Neurology (Minneapolis), 25, 31-36.

Cracco, R. Q. (1973). Spinal evoked response: peripheral nerve stimulation in man. Electroencephalography and Clinical Neurophysiology, 35, 379-386.

Eccles, J. C., Kostyuk, P. G., and Schmidt, R. F. (1962). Central pathways responsible for depolarization of primary afferent fibres. Journal of Physiology, 161, 237-257.

Eisen, A., Schomer, D., and Melmed, C. (1977). An electrophysiological method for examining lumbosacral root compression. Canadian Journal of Neurological Sciences, 4, 117-123.

Ertekin, C. (1973). Human evoked electrospinogram. In New Developments in Electromyography and Clinical Neurophysiology. Vol. 2, pp. 344-351. Edited J. E. Desmedt. Karger: Basel.

Ertekin, C. (1976). Studies on the human evoked electrospinogram. 1. The origin of the segmental evoked potentials. Acta Neurologica Scandinavica, 53, 3-20.

Gasser, H. S., and Graham, H. I. (1933). Potentials produced in the spinal cord by stimulation of dorsal roots. American Journal of Physiology, 103, 303-320.

Giblin, D. R. (1964). Somatosensory evoked potentials in healthy subjects and in patients with lesions of the nervous system. Annals of the New York Academy of Sciences, 112, 93-142.

Gilliatt, R. W., and Willison, R. G. (1963). The refractory and supernormal periods of the human median nerve. Journal of Neurology, Neurosurgery, and Psychiatry, 26, 136-147.

Kopec, S. J., Delbeke, J., and McComas, A. J. (1978). Refractory period studies in a human neuromuscular preparation. Journal of Neurology, Neurosurgery, and Psychiatry, 41, 54-64.

Liberson, W. T., and Kim, K. C. (1963). Mapping evoked potentials elicited by stimulation of the median and peroneal nerves. Electroencephalography and Clinical Neurophysiology, 15, 721.

Lowitzsch, K., and Hopf, H. C. (1972). Refraktarperiode und Uber mittlung frequenter Reizserien 
im gemischten peripheren Nerven des Menschen. Journal of the Neurological Sciences, 17, 255-270.

Magladery, J. W., and McDougal, D. B. (1950). Electrophysiological studies of nerve and reflex activity in normal man. $I$. Identification of certain reflexes in the electromyogram and the conduction velocity of peripheral nerve fibers. Bulletin of the Johns Hopkins Hospital, 86, 265-290.

Magladery, J. W., Porter, W. E., Park, A. M., and Teasdall, R. D. (1951). Electrophysiological studies of nerve and reflex activity in normal man. IV. The two-neurone reflex and identification of certain action potentials from spinal roots and cord. Bulletin of the Johns Hopkins Hospital, 88, 499-519.
Shimoji, K., Higashi, H., and Kano, T. (1971). Epidural recording of spinal electrogram in man. Electroencephalography and Clinical Neurophysiology, 30, 236-239.

Shimoji, K., Kano, T., Higashi, H., Morioka, T., and Henschel, E. O. (1972). Evoked spinal electrograms recorded from epidural space in man. Journal of Applied Physiology, 33, 468-471.

Wall, P. D. (1958). Excitability change in afferent fibre terminations and their relation to slow potentials. Journal of Physiology, 142, 1-21. 